\title{
Hybridization chain reaction enables a unified approach to multiplexed, quantitative, high-resolution immunohistochemistry and in situ hybridization
}

\author{
Maayan Schwarzkopf, ${ }^{1, \dagger}$ Mike C. Liu, ${ }^{2, \dagger}$ Samuel J. Schulte, ${ }^{1, \ddagger}$ Rachel Ives, ${ }^{2, \ddagger}$ N. Husain, ${ }^{1}$ Harry M.T. Choi ${ }^{2, *}$ \\ and Niles A. Pierce ${ }^{1,3, *}$
}

\begin{abstract}
RNA in situ hybridization (RNA-ISH) based on the mechanism of hybridization chain reaction (HCR) enables multiplexed, quantitative, high-resolution RNA imaging in highly autofluorescent samples including whole-mount vertebrate embryos, thick brain slices, and formalin-fixed paraffin-embedded (FFPE) tissue sections. Here, we extend the benefits of 1-step, multiplexed, quantitative, isothermal, enzyme-free HCR signal amplification to immunohistochemistry (IHC), enabling accurate and precise protein relative quantitation with subcellular resolution in an anatomical context. Moreover, we provide a unified framework for simultaneous quantitative protein and RNA imaging with 1-step HCR signal amplification performed for all target proteins and RNAs simultaneously.
\end{abstract}

KEYWORDS: Immunofluorescence (IF), RNA fluorescence in situ hybridization (RNA-FISH), qHCR imaging, formalinfixed paraffin-embedded (FFPE) mouse brain and human breast tissue sections, whole-mount zebrafish embryos.

SUMMARY: Signal amplification based on the mechanism of hybridization chain reaction enables multiplexed, quantitative, highresolution imaging of protein and RNA targets in highly autofluorescent tissues.

\section{INTRODUCTION}

Biological circuits encoded in the genome of each organism direct development, maintain integrity in the face of attacks, control responses to environmental stimuli, and sometimes malfunction to cause disease. RNA in situ hybridization (RNA-ISH) methods (Gall \& Pardue, 1969; Cox et al., 1984; Tautz \& Pfeifle, 1989; Rosen \& Beddington, 1993; Wallner et al., 1993; Nieto et al., 1996; Thisse \& Thisse, 2008) and immunohistochemistry (IHC) methods (Coons et al., 1941; Takakura et al., 1997; Sillitoe \& Hawkes, 2002; Ahnfelt-Ronne et al., 2007; Psychoyos \& Finnell, 2009; Ramos-Vara \& Miller, 2014; Fujisawa et al., 2015; Staudt et al., 2015) provide biologists, drug developers, and pathologists with critical windows into the spatial organization of this circuitry, enabling imaging of RNA and protein expression in an anatomical context. While it is desirable to perform multiplexed experiments in which a panel of targets are imaged quantitatively at high resolution in a single specimen, using traditional RNA-ISH and IHC methods in highly autofluorescent samples including whole-mount vertebrate embryos and FFPE tissue sections, multiplexing is cumbersome, staining is non-quantitative, and

${ }^{1}$ Division of Biology \& Biological Engineering, California Institute of Technology, Pasadena, CA 91125, USA. ${ }^{2}$ Molecular Instruments, Inc., Los Angeles, CA 90041, USA. ${ }^{3}$ Division of Engineering \& Applied Science, California Institute of Technology, Pasadena, CA 91125, USA. ${ }^{\dagger}$ Authors contributed equally. $\ddagger$ Authors contributed equally.

*Authors for correspondence (niles@caltech.edu and

harry@molecularinstruments.com) spatial resolution is routinely compromised by diffusion of reporter molecules. These multi-decade technological shortcomings are significant impediments to biological research as well as to advancement of drug development and pathology assays, impeding high-dimensional, quantitative, high-resolution analyses of developmental and disease-related regulatory networks in an anatomical context.

RNA-ISH methods detect RNA targets using nucleic acid probes (Qian et al., 2004; Silverman \& Kool, 2007) and IHC methods detect protein targets using antibody probes (Ramos-Vara \& Miller, 2014). In either case, probes can be direct-labeled with reporter molecules (Kislauskis et al., 1993; Femino et al., 1998; Levsky et al., 2002; Kosman et al., 2004; Capodieci et al., 2005; Chan et al., 2005; Raj et al., 2008), but to increase the signal-to-background ratio, are more often used to mediate signal amplification in the vicinity of the probe (Qian et al., 2004; Silverman \& Kool, 2007; RamosVara \& Miller, 2014). A variety of in situ amplification approaches have been developed including immunological methods (Macechko et al., 1997; Hughes \& Krause, 1998; Kosman et al., 2004), branched DNA methods (Collins et al., 1997; Bushnell et al., 1999; Player et al., 2001; Qian \& Lloyd, 2003; Wang et al., 2012; Kishi et al., 2019; Saka et al., 2019), in situ PCR methods (Wiedorn et al., 1999; Qian \& Lloyd, 2003), and rolling circle amplification methods (Zhou et al., 2001; Schweitzer \& Kingsmore, 2001; Larsson et al., 2004; Zhou et al., 2004; Larsson et al., 2010). However, for both RNAISH (Tautz \& Pfeifle, 1989; Harland, 1991; Lehmann \& Tautz, 1994; Kerstens et al., 1995; Nieto et al., 1996; Pernthaler et al., 2002; Kosman et al., 2004; Thisse et al., 2004; Denkers et al., 2004; Clay \& Ramakrishnan, 2005; Barroso-Chinea et al., 2007; Acloque et al., 2008; Piette et al., 2008; Thisse \& Thisse, 2008; Weiszmann et al., 2009; Wang et al., 2012) and IHC (Takakura et al., 1997; Sillitoe \& Hawkes, 2002; Ahnfelt-Ronne et al., 2007; Psychoyos \& Finnell, 2009; Ramos-Vara \& Miller, 2014; Fujisawa et al., 2015; Staudt et al., 2015), traditional in situ amplification based on enzyme-mediated catalytic reporter deposition (CARD) remains the dominant approach for achieving high signal-to-background in highly autofluorescent samples including whole-mount vertebrate embryos and FFPE tissue sections. CARD is widely used despite three significant drawbacks: multiplexing is cumbersome due to the lack of orthogonal deposition chemistries, necessitating serial amplification for one target after another (Lehmann \& Tautz, 1994; Nieto et al., 1996; Thisse et al., 2004; Denkers et al., 2004; Kosman et al., 2004; Clay \& Ramakrishnan, 2005; Barroso-Chinea et al., 2007; Tóth \& Mezey, 2007; Acloque et al., 2008; Piette et al., 2008; Glass et al., 2009; Stack et al., 2014; Mitchell et al., 2014; Tsujikawa et al., 2017), staining is qualitative rather than quantitative, and spatial resolution is routinely 


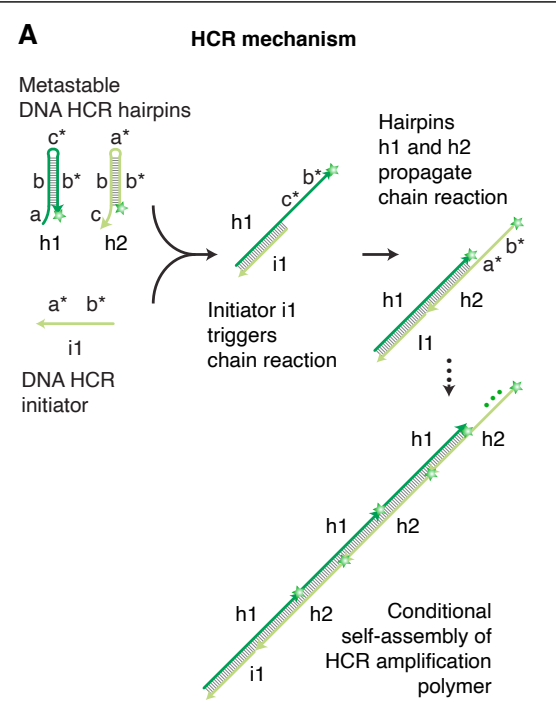

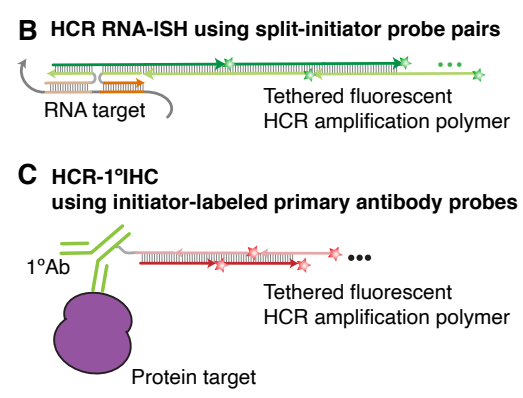

D HCR-2 IHC

using unlabeled primary antibody probes and initiator-labeled secondary antibody probes

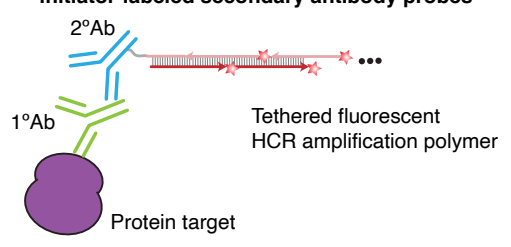

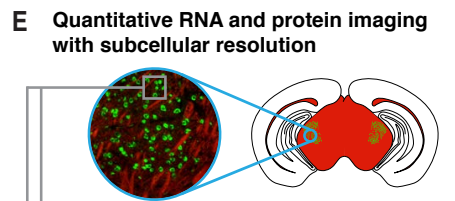
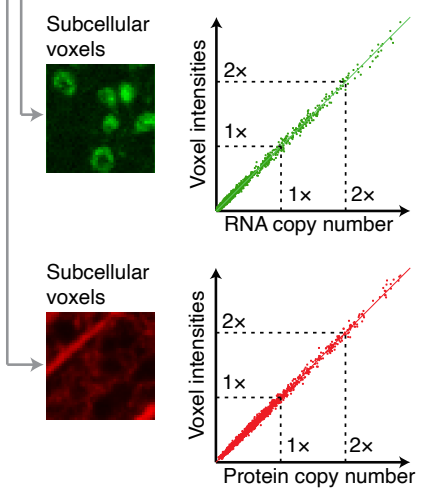

Fig. 1: A unified framework for multiplexed, quantitative, high-resolution protein and RNA imaging using HCR $1^{\circ}$ IHC + HCR RNA-ISH or HCR $2^{\circ}$ IHC + RNA-ISH. (A) 1-step, isothermal, enzyme-free signal amplification via hybridization chain reaction (HCR) (Dirks \& Pierce, 2004). Kinetically trapped hairpins h1 and h2 co-exist metastably in solution on lab time scales, storing the energy to drive a conditional self-assembly cascade upon exposure to a cognate initiator sequence i1. Stars denote fluorophores. (B) HCR RNA-ISH using split-initiator probe pairs that hybridize to adjacent binding sites on the target RNA to colocalize a full HCR initiator and trigger HCR. (C) HCR $1^{\circ}$ IHC using initiator-labeled primary antibody probes. (D) HCR $2^{\circ} \mathrm{IHC}$ using unlabeled primary antibody probes and initiator-labeled secondary antibody probes. (E) Conceptual schematic: HCR signal scales approximately linearly with the abundance of a target RNA (green channel) or protein (red channel), enabling accurate and precise relative quantitation with subcellular resolution in an anatomical context.

compromised by diffusion of reporter molecules prior to deposition (Tautz \& Pfeifle, 1989; Takakura et al., 1997; Sillitoe \& Hawkes, 2002; Thisse et al., 2004; Thisse \& Thisse, 2008; Acloque et al., 2008; Piette et al., 2008; Weiszmann et al., 2009; Psychoyos \& Finnell, 2009).

In the context of RNA-ISH, in situ amplification based on the mechanism of hybridization chain reaction (HCR; Figure 1A) (Dirks \& Pierce, 2004) overcomes the longstanding shortcomings of CARD to enable multiplexed, quantitative, high-resolution imaging of RNA expression in diverse organisms and sample types including highly autofluorescent samples (Choi et al., 2010; Choi et al., 2014; Choi et al., 2016; Shah et al., 2016; Trivedi et al., 2018; Choi et al., 2018) (e.g., see Table S1). To image RNA expression, targets are detected by nucleic acid probes that trigger isothermal enzymefree chain reactions in which fluorophore-labeled HCR hairpins self-assemble into tethered fluorescent amplification polymers (Figure 1B). Orthogonal HCR amplifiers operate independently within the sample so the experimental timeline for multiplexed experiments is independent of the number of target RNAs (Choi et al., 2010; Choi et al., 2014). The amplified HCR signal scales approximately linearly with the number of target molecules (Figure 1E), enabling accurate and precise RNA relative quantitation with subcellular resolution in the anatomical context of whole-mount vertebrate embryos (Trivedi et al., 2018; Choi et al., 2018). Amplification polymers remain tethered to their initiating probes, enabling imaging of RNA expression with subcellular or single-molecule resolution as desired (Choi et al., 2014; Shah et al., 2016; Choi et al., 2016; Choi et al., 2018).

These properties that make HCR signal amplification wellsuited for RNA-ISH appear equally favorable in the context of IHC, suggesting the approach of combining HCR signal amplification with antibody probes (Koos et al., 2015; Husain, 2016; Lin et al., 2018). Here, we extend the benefits of 1-step, quantitative, enzyme-free signal amplification from RNA-ISH to IHC, validating multiplexed, quantitative, high-resolution imaging of protein expression with high signal-to-background in highly autofluorescent samples, thus overcoming the longstanding shortcomings of IHC using CARD. Moreover, we establish a unified framework for simultaneous multiplexed, quantitative, high-resolution IHC and RNA-ISH, with 1-step HCR signal amplification performed for all targets simultaneously.

\section{RESULTS}

For protein imaging with HCR, we pursue two complementary approaches. Using $\mathrm{HCR} 1^{\circ} \mathrm{IHC}$, protein targets are detected using primary antibody probes labeled with one or more HCR initiators (Figure 1C). For multiplexed experiments, the probes for different targets are labeled with different HCR initiators that trigger orthogonal HCR amplifiers labeled with spectrally distinct fluorophores. Researchers have the flexibility to detect different targets using primary antibody probes raised in the same host species (or a variety of host species as convenient). On the other hand, antibody-initiator conjugation must be validated for each new primary antibody probe. Using HCR $2^{\circ} \mathrm{IHC}$, protein targets are detected using unlabeled primary antibody probes that are in turn detected by secondary antibody probes labeled with one or more HCR initiators (Figure 1D). This approach has the advantage that validation of a small library of initiator-labeled secondary antibodies (e.g., 5 secondaries targeting different host species) enables immediate use of large libraries of primary antibody probes (e.g., $10^{5}$ commercially available primaries) without modification. On the other hand, for multiplexed experiments, each target must be detected using a primary antibody raised in a different host species to enable subsequent detection by an anti-host secondary antibody probe that triggers an orthogonal spectrally distinct HCR amplifier. Hence, depending on 
A Detection stage

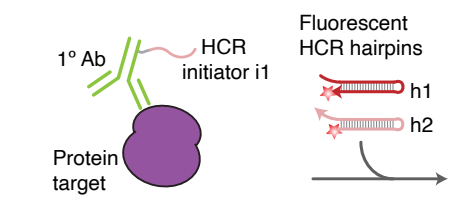

Amplification stage

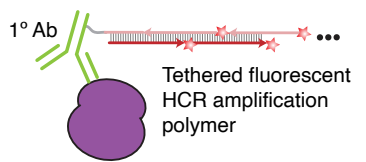

B Detection stage

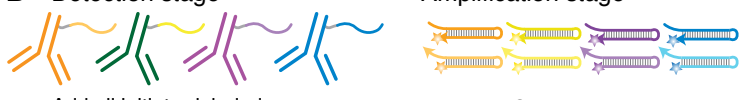

Add all initiator-labeled

$1^{\circ}$ antibody probes
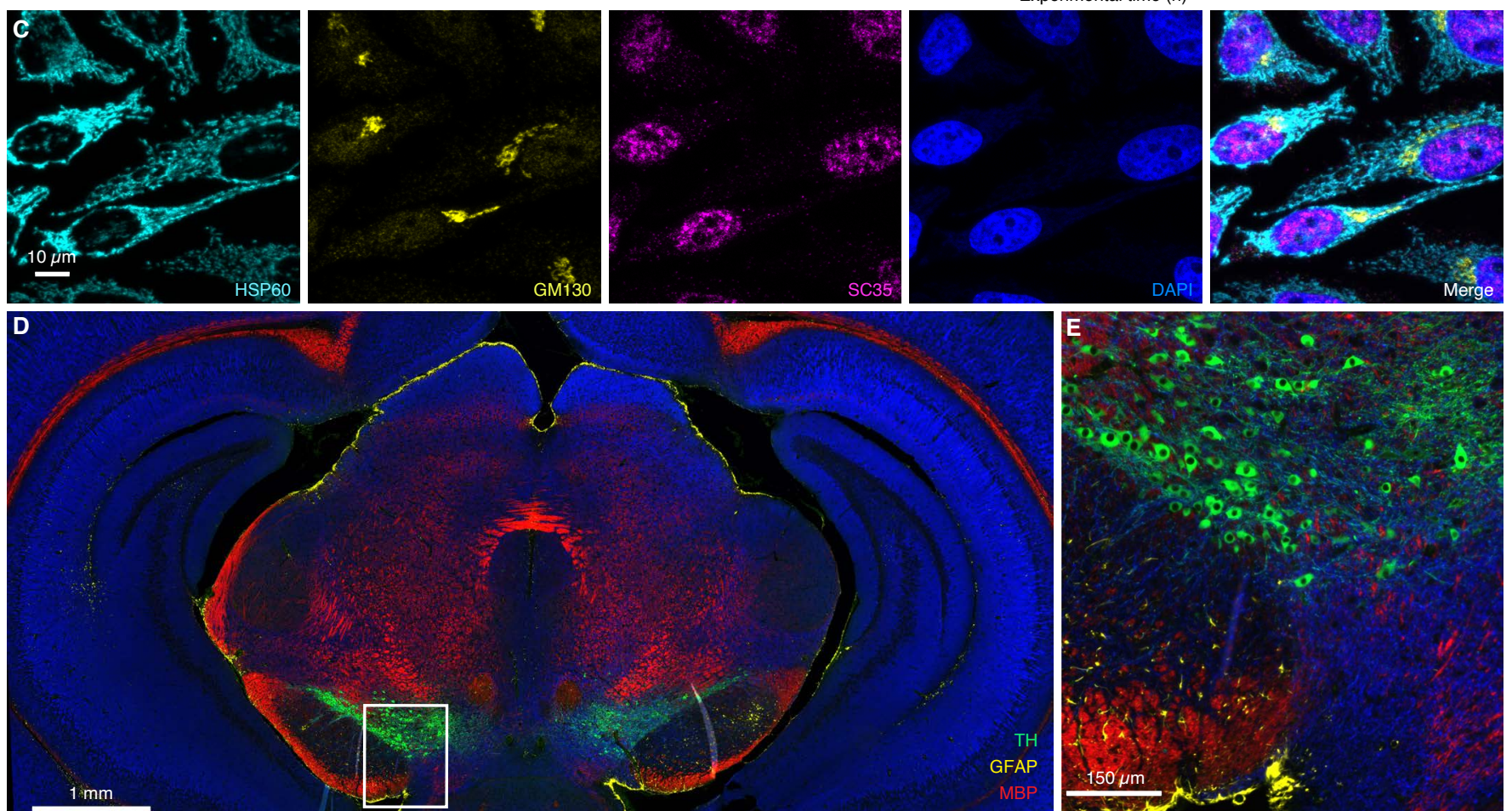

(1)
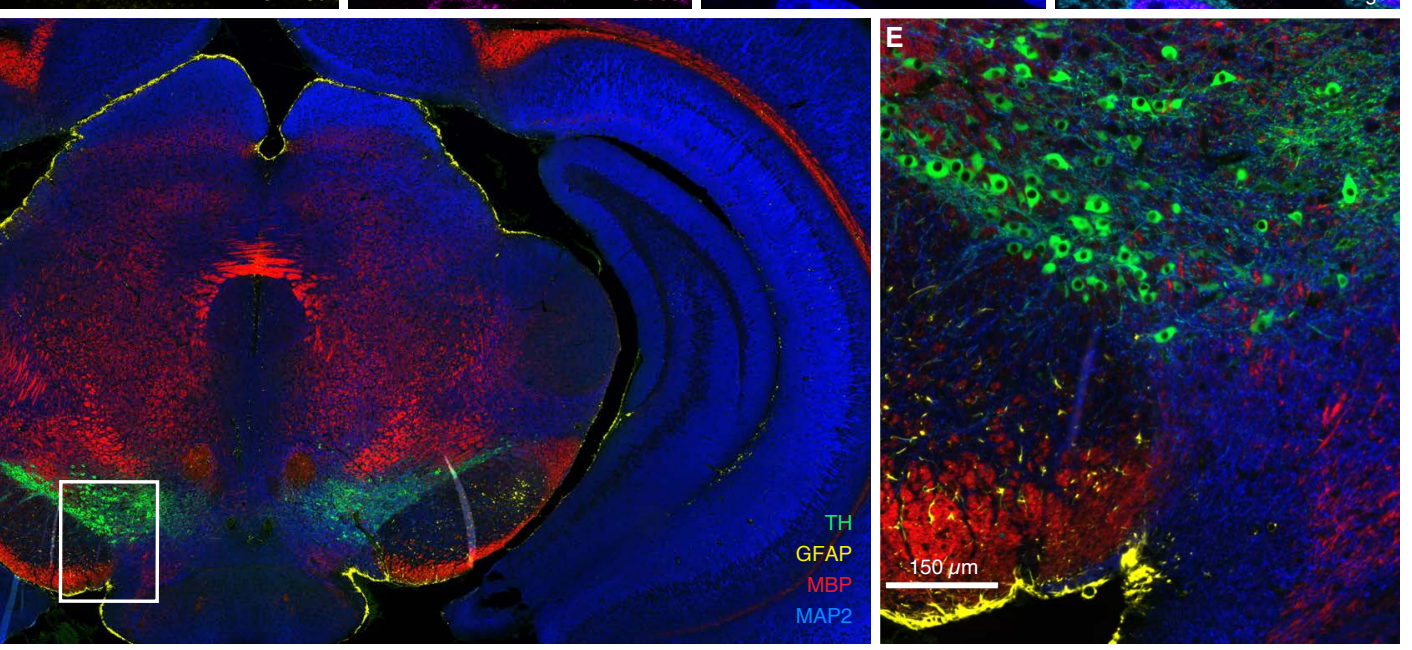

Fig. 2: Multiplexed protein imaging via HCR $1^{\circ} \mathrm{IHC}$ using initiator-labeled primary antibody probes and simultaneous $\mathrm{HCR}$ signal amplification for all targets. (A) 2-stage IHC protocol. Detection stage: initiator-labeled primary antibody probes bind to protein targets; wash. Amplification stage: initiators trigger self-assembly of fluorophore-labeled HCR hairpins into tethered fluorescent amplification polymers; wash. (B) Multiplexing timeline. The same 2-stage protocol is used independent of the number of target proteins. (C) Confocal image of 3-plex protein imaging in mammalian cells on a slide; $0.2 \times 0.2 \mu \mathrm{m}$ pixels; maximum intensity z-projection. Target proteins: HSP60 (Alexa488), GM130 (Alexa647), SC35 (Alexa546). Sample: HeLa cells. (D) Epifluorescence image of 4-plex protein imaging in FFPE mouse brain sections; $0.3 \times 0.3$ $\mu \mathrm{m}$ pixels. Target proteins: TH (Alexa488), GFAP (Alexa546), MBP (Alexa647), MAP2 (Alexa750). (E) Zoom of depicted region of panel D. Sample: FFPE C57BL/6 mouse brain section (coronal); thickness: $5 \mu \mathrm{m}$. See Section S5.2 for additional data.

the available antibody probes, one may prefer $\mathrm{HCR} 1^{\circ} \mathrm{IHC}$ in one instance and $\mathrm{HCR} 2^{\circ} \mathrm{IHC}$ in another.

\section{Multiplexed protein imaging using HCR $1^{\circ} \mathrm{IHC}$ or HCR}

$2^{\circ}$ IHC. Figure 2 demonstrates multiplexed protein imaging via $\mathrm{HCR} 1^{\circ} \mathrm{IHC}$ using initiator-labeled primary antibody probes. Figure 3 demonstrates multiplexed protein imaging via $\mathrm{HCR} 2^{\circ} \mathrm{IHC}$ using unlabeled primary antibody probes and initiator-labeled secondary antibody probes. Both methods achieve high signal-to-background for 3-plex protein imaging in mammalian cells and for 4-plex protein imaging in FFPE mouse brain sections. Across 21 protein imaging scenarios (6 in mammalian cells +10 in FFPE mouse brain sections +4 in FFPE human breast tissue sections +1 in whole-mount zebrafish embryos; 9 using $1^{\circ} \mathrm{IHC} \mathrm{HCR}+13$ using $2^{\circ} \mathrm{IHC} \mathrm{HCR}$; 11 using confocal microscopy +10 using epifluorescence microscopy), the estimated signal-to-background ratio for protein targets ranged from 20 to 610 with a median of 87 (see Tables S9 and S10 for additional details). This level of performance was achieved for all targets simultaneously in 4-channel and 5-channel images (including a DAPI channel in each case) using fluorophores that compete with lower autofluorescence
(Alexa647) as well as with higher autofluorescence (Alexa488) and in samples with lower autofluorescence (mammalian cells) and higher autofluorescence (FFPE mouse brain sections).

Using HCR signal amplification, the amplification gain corresponds to the number of fluorophore-labeled hairpins per amplification polymer. Hence, we were curious to measure the mean HCR polymer length in the context of HCR $1^{\circ} \mathrm{IHC}$ and HCR $2^{\circ} \mathrm{IHC}$ experiments. We can estimate HCR amplification gain by comparing the signal intensity in HCR experiments using $\mathrm{h} 1$ and $\mathrm{h} 2$ hairpins together (enabling polymerization to proceed as normal) vs using only hairpin h1 (so that each HCR initiator can bind only one HCR hairpin and polymerization cannot proceed). Across 4 measurement scenarios (2 in mammalian cells +2 in FFPE mouse brain sections; 2 using $\mathrm{HCR} 1^{\circ} \mathrm{IHC}$ and 2 using $\mathrm{HCR} 2^{\circ} \mathrm{IHC}$ ) we observed a median polymer length of $\approx 180$ hairpins (Section S5.5). It is this amplification gain that boosts the signal above autofluorescence to yield high signal-to-background even in FFPE tissues and whole-mount vertebrate embryos.

qHCR imaging: protein relative quantitation with subcellular resolution in an anatomical context. We previously demon- 
bioRxiv preprint doi: https://doi.org/10.1101/2021.06.02.446311; this version posted June 2, 2021. The copyright holder for this preprint (which was not certified by peer review) is the author/funder. All rights reserved. No reuse allowed without permission.

A Detection stage
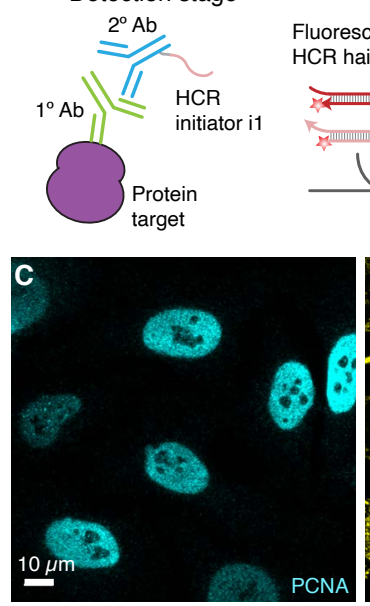

D

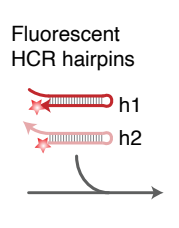

Amplification stage
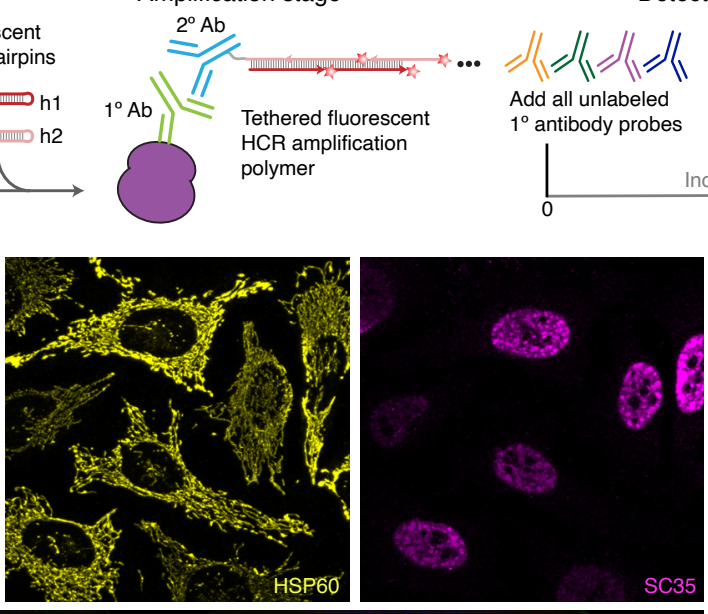

Tethered fluorescent $\quad \begin{array}{ll}\text { Add all unlabeled } \\ 1^{\circ} \text { antibody probes }\end{array}$ HCR amplification polymer

B

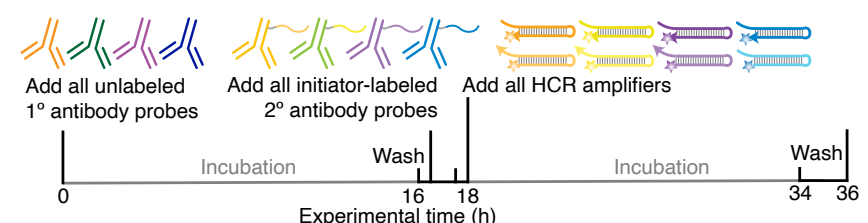

mental time $(\mathrm{h})$
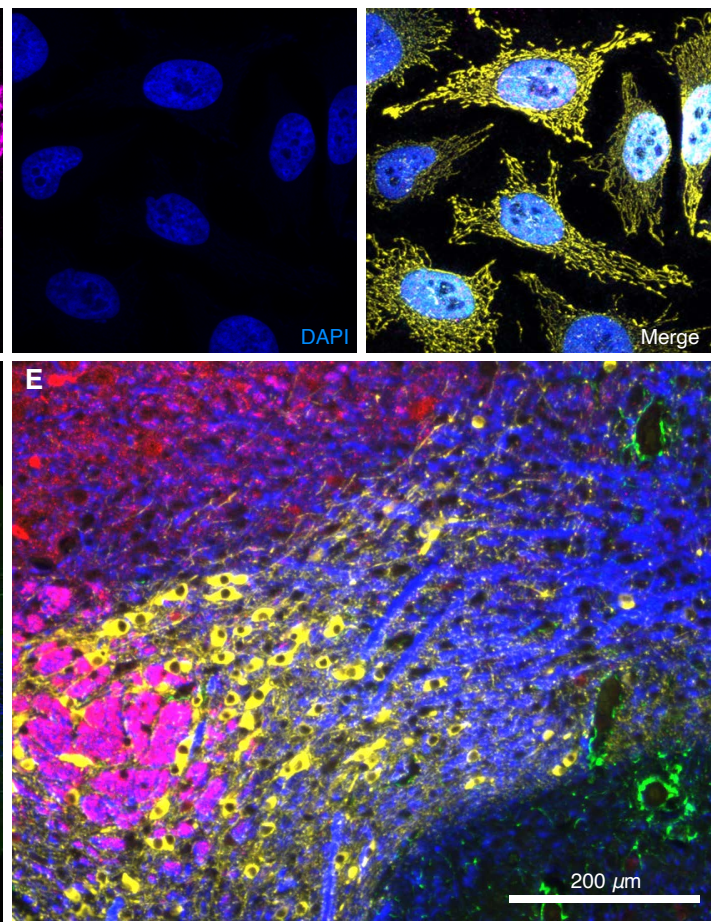

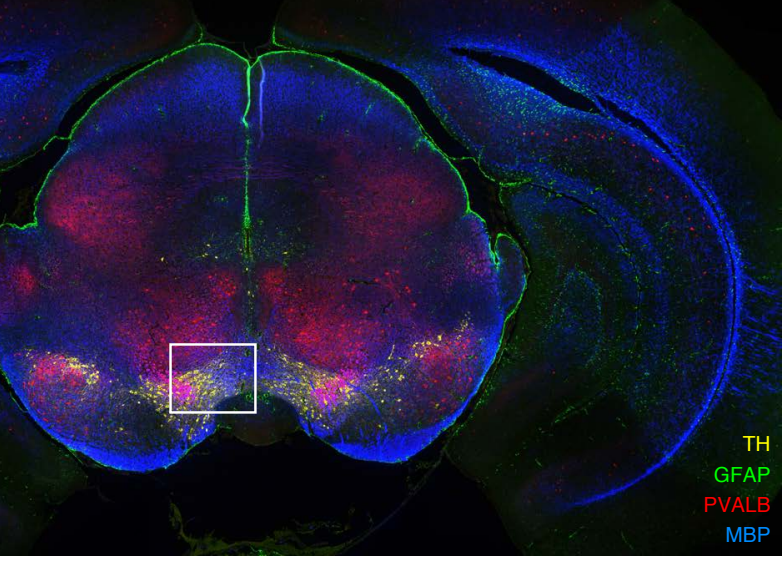

Fig. 3: Multiplexed protein imaging via HCR $2^{\circ} \mathrm{IHC}$ using unlabeled primary antibody probes, initiator-labeled secondary antibody probes, and simultaneous HCR signal amplification for all targets. (A) 2-stage IHC protocol. Detection stage: unlabeled primary antibody probes bind to protein targets; wash; initiator-labeled secondary antibody probes bind to primary antibody probes; wash. Amplification stage: initiators trigger self-assembly of fluorophore-labeled HCR hairpins into tethered fluorescent amplification polymers; wash. (B) Multiplexing timeline. The same 2-stage protocol is used independent of the number of target proteins. (C) Confocal image of 3-plex protein imaging in mammalian cells on a slide; $0.14 \times 0.14 \mu \mathrm{m}$ pixels; maximum intensity z-projection. Target proteins: PCNA (Alexa647), HSP60 (Alexa546), SC35 (Alexa488). Sample: HeLa cells. (D) Epifluorescence image of 4-plex protein imaging in FFPE mouse brain sections; $0.6 \times 0.6 \mu \mathrm{m}$ pixels. Target proteins: TH (Alexa488), GFAP (Alexa546), PVALB (Alexa647), MBP (Alexa750). (E) Zoom of depicted region of panel D. Sample: FFPE C57BL/6 mouse brain section (coronal); thickness: $5 \mu \mathrm{m}$. See Section S5.3 for additional data.

strated that HCR RNA-ISH overcomes the historical tradeoff between RNA quantitation and anatomical context, enabling mRNA relative quantitation (qHCR imaging) with subcellular resolution within whole-mount vertebrate embryos (Trivedi et al., 2018; Choi et al., 2018). Here, we demonstrate that HCR IHC enables analogous subcellular quantitation of proteins in an anatomical context. To test protein relative quantitation, we first redundantly detected a target protein using two primary antibody probes that bind different epitopes on the same protein and trigger different spectrally-distinct HCR amplifiers (Figure 4A; top), yielding a 2-channel image (Figure 4B; top). If HCR signal scales approximately linearly with the number of target proteins per voxel, a 2-channel scatter plot of normalized voxel intensities will yield a tight linear distribution with approximately zero intercept (Trivedi et al., 2018). Conversely, observing a tight linear distribution with approximately zero intercept (Figure 4C; top), we conclude that the HCR signal scales approximately linearly with the number of target proteins per imaging voxel, after first ruling out potential systematic crowding effects that could permit pairwise voxel intensities to slide undetected along a line (Supplementary Figure S24). Using one initiator-labeled pri- mary antibody probe per channel, we observe high accuracy (linearity with zero intercept) and precision (scatter around the line) for subcellular $2 \times 2 \mu \mathrm{m}$ voxels within FFPE mouse brain sections. Note that this redundant detection experiment provides a conservative characterization of quantitative performance since there is the risk that two antibody probes may interfere with each other to some extent when attempting to bind different epitopes on the same target protein. As a further test of quantitative imaging characteristics, we detected a protein target with unlabeled primary antibody probes that are subsequently detected by two batches of secondary antibody probes that trigger different spectrally-distinct HCR amplifiers (Figure 4A; bottom). This experiment is testing the accuracy and precision of the secondary antibody probes and HCR signal amplification, but not that of the primary antibody probes. In FFPE human breast tissue sections (Figure $4 \mathrm{~B}$; bottom), a 2-channel scatter plot of voxel intensities for subcellular $2 \times 2 \mu \mathrm{m}$ voxels again reveals a tight linear distribution with approximately zero intercept (Figure $4 \mathrm{C}$; bottom). Based on these two studies, we conclude that qHCR imaging enables accurate and precise relative quantitation of protein targets in an anatomical context with subcellular res- 

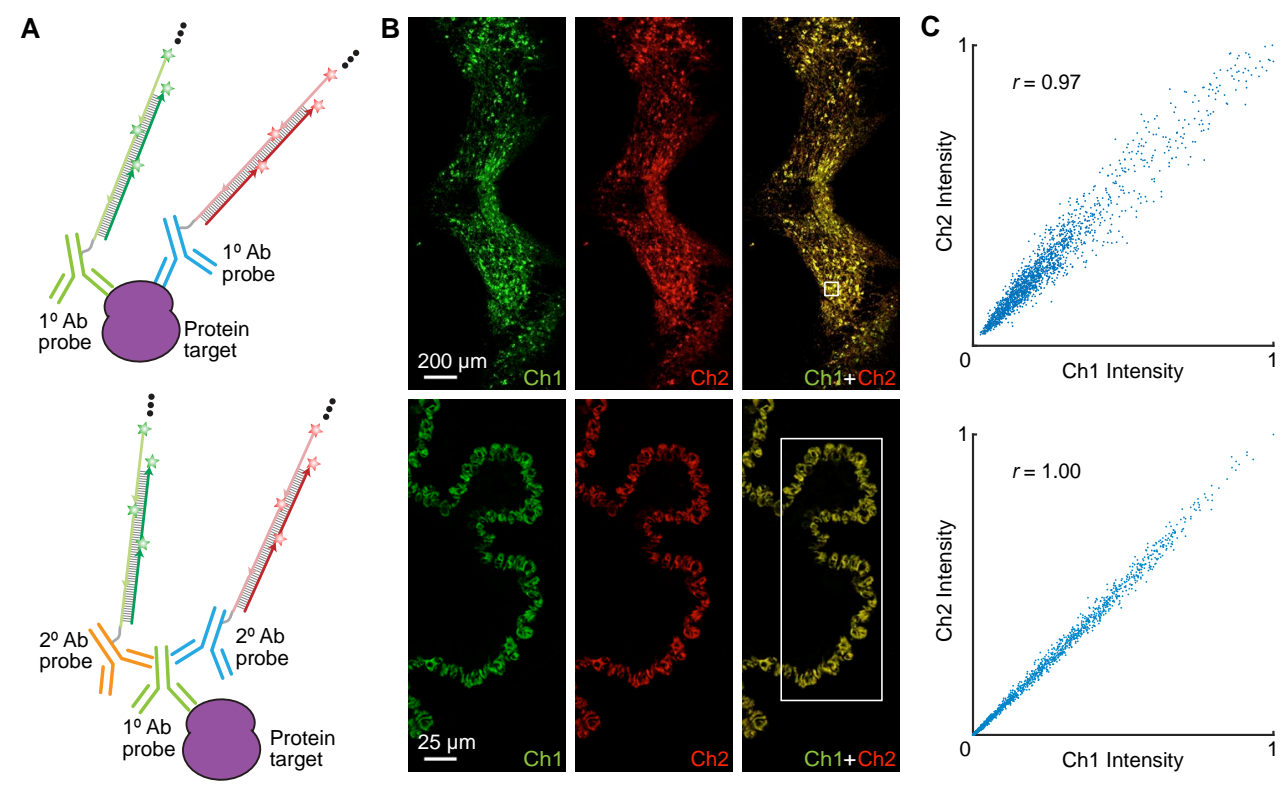

Fig. 4: qHCR imaging: protein relative quantitation with subcellular resolution in an anatomical context using $\mathrm{HCR} 1^{\circ} \mathrm{IHC}$ or $\mathrm{HCR} 2^{\circ}$ IHC. (A) 2-channel redundant detection of a target protein. Top: target protein detected using two primary antibody probes that bind different epitopes, each initiating an orthogonal spectrally distinct HCR amplifier (Ch1: Alexa647, Ch2: Alexa750). Bottom: target protein detected using unlabeled primary antibody probes and two batches of secondary antibody probes that initiate orthogonal spectrally distinct HCR amplifiers (Ch1: Alexa546, Ch2: Alexa647). (B) Top: Epifluorescence image of FFPE mouse brain section; $0.16 \times 0.16 \mu \mathrm{m}$ pixels. Target protein: TH. Sample: FFPE C57BL/ 6 mouse brain section (coronal); thickness: $5 \mu \mathrm{m}$. Bottom: Confocal image of FFPE human breast tissue; $0.3 \times 0.3 \mu \mathrm{m}$ pixels; single optical section. Target protein: KRT17. Sample: FFPE human breast tissue section; thickness: $5 \mu \mathrm{m}$. (C) High accuracy and precision for protein relative quantitation in an anatomical context. Highly correlated normalized signal (Pearson correlation coefficient, $r$ ) for subcellular voxels $(2 \times 2 \mu \mathrm{m})$ in the depicted region of panel B. Accuracy: linearity with zero intercept. Precision: scatter around the line. See Section S5.6 for additional data.

olution, just as it does for mRNA targets (Trivedi et al., 2018; Choi et al., 2018).

Simultaneous multiplexed protein and RNA imaging using
HCR $1^{\circ}$ IHC + HCR RNA-ISH or HCR $2^{\circ}$ IHC + HCR RNA-

ISH. It is important for biologists, drug developers, and pathologists to have the flexibility to image proteins and RNAs simultaneously so as to enable interrogation of both levels of gene expression in the same specimen. Here, we demonstrate that $\mathrm{HCR} 1^{\circ} \mathrm{IHC}$ and $\mathrm{HCR} 2^{\circ} \mathrm{IHC}$ are both compatible with HCR RNA-ISH, enabling multiplexed quantitative protein and RNA imaging with high signal-to-background. Figure 5 demonstrates HCR $1^{\circ} \mathrm{IHC}+\mathrm{HCR}$ RNA-ISH (2-plex protein +2 -plex RNA) in mammalian cells and FFPE mouse brain sections using initiator-labeled primary antibody probes for protein targets, split-initiator DNA probes for RNA targets, and simultaneous HCR signal amplification for all targets. Figure 6 demonstrates HCR $2^{\circ} \mathrm{IHC}+\mathrm{HCR}$ RNA-ISH (2-plex protein +2 -plex RNA) in mammalian cells and FFPE mouse brain sections using unlabeled primary antibody probes and initiator-labeled secondary antibody probes for protein targets, split-initiator DNA probes for RNA targets, and simultaneous HCR signal amplification for all targets. Across 16 protein and RNA imaging scenarios ( 8 in mammalian cells + 8 in FFPE mouse brain sections; 8 using $1^{\circ} \mathrm{IHC} \mathrm{HCR}+\mathrm{HCR}$ RNA-ISH +8 using $2^{\circ} \mathrm{IHC}$ HCR + HCR RNA-ISH; 8 using confocal microscopy +8 using epifluorescence microscopy), the estimated signal-to-background ratio for each target protein or RNA ranged from 14 to 280 with a median of 43 (see Tables S9 and S11 for additional details).

\section{DISCUSSION}

qHCR imaging enables a unified approach to multiplexed quantitative IHC and RNA-ISH. A single experiment yields accurate and precise relative quantitation of both protein and RNA targets with subcellular resolution in the anatomical context of highly autofluorescent samples. Note that no extra work is necessary to perform quantitative imaging - it is a natural property of HCR signal amplification. Here, we validated two complementary approaches for HCR IHC. Using HCR $1^{\circ} \mathrm{IHC}$ (initiator-labeled primary antibody probes), each target protein in a multiplexed experiment can be detected with antibodies raised in the same host species, which is often convenient based on available antibody libraries. However, antibody-initiator conjugation must be validated for each new primary antibody probe. Alternatively, using $\mathrm{HCR} 2^{\circ} \mathrm{IHC}$ (unlabeled primary antibody probes and initiator-labeled secondary antibody probes), each target protein in a multiplexed experiment must be detected with primary antibodies raised in different host species, thus enabling subsequent binding by initiator-labeled secondary antibodies that react with those different host species. This approach has the benefit that a small library of initiator-labeled secondary antibodies can be validated a priori and then used with large libraries of (unmodified) validated primary antibodies, enabling a plug-and-play approach using validated reagents. For simultaneous protein and RNA imaging: during the protein detection stage, $\mathrm{M}$ target proteins are detected in parallel; during the RNA detection stage, $\mathrm{N}$ target RNAs are detected in parallel; and during the amplification stage, 1-step quantitative HCR signal amplification is performed for all $\mathrm{M}+\mathrm{N}$ protein and RNA targets simultaneously. In 4-plex experiments in FFPE tissue sections, protein and RNA targets are simultaneously imaged with high signal-to-background in all 4 channels using fluorophores that 
A Protein detection stage

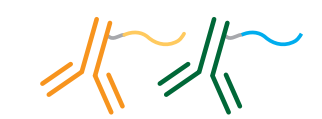

Add all initiator-labeled $1^{\circ}$ antibody probes
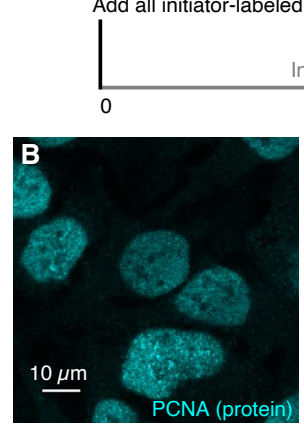

Incubation
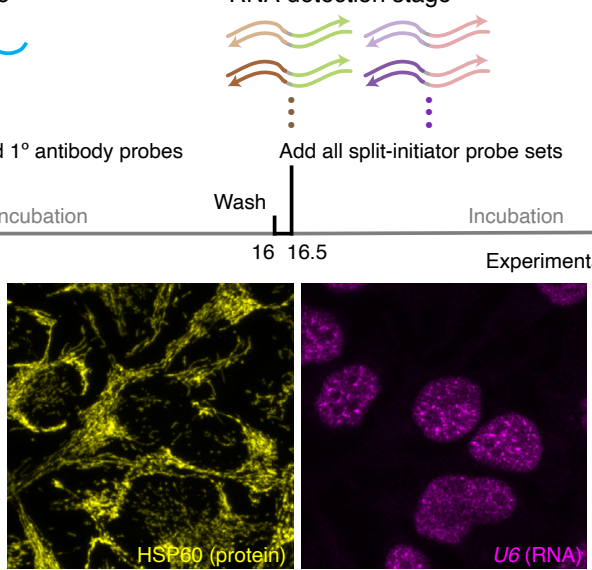

Add all split-initiator probe sets $\quad$ Add all HCR amplifiers

C
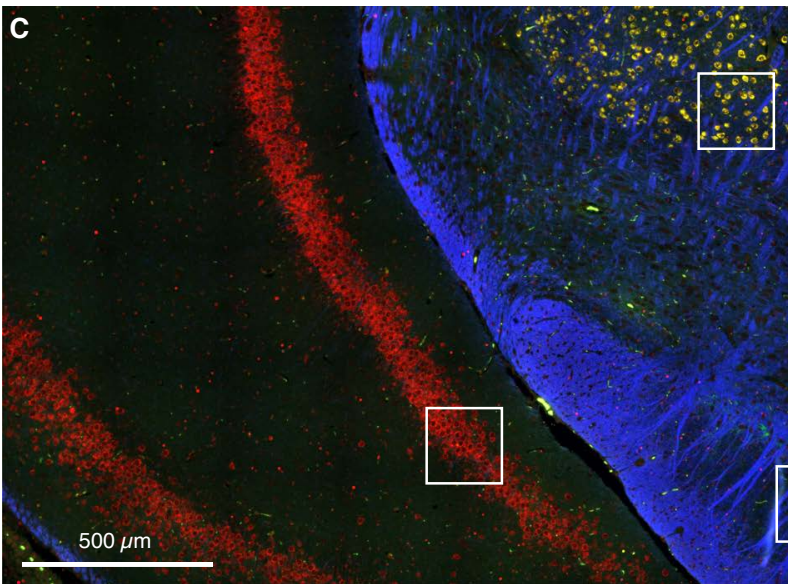

Experimental time $(h)$

Amplification stage (all targets)
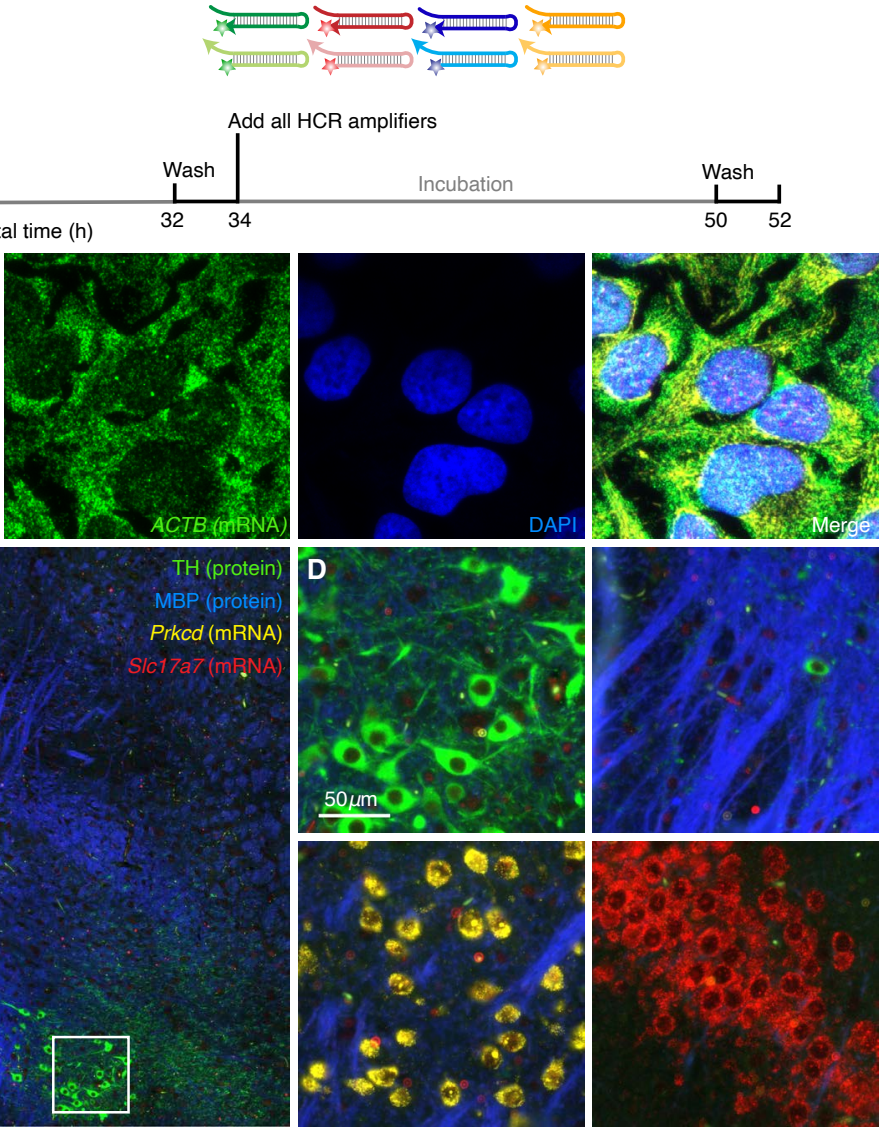

Fig. 5: Simultaneous multiplexed protein and RNA imaging via HCR $1^{\circ} \mathrm{IHC}+\mathrm{HCR}$ RNA-ISH using initiator-labeled primary antibody probes for protein targets, split-initiator DNA probes for RNA targets, and simultaneous HCR signal amplification for all targets. (A) 3-stage IHC + RNA-ISH protocol. Protein detection stage: initiator-labeled primary antibody probes bind to protein targets; wash. RNA detection stage: split-initiator DNA probes bind to RNA targets; wash. Amplification stage: initiators trigger self-assembly of fluorophore-labeled HCR hairpins into tethered fluorescent amplification polymers; wash. For multiplexed experiments, the same 3-stage protocol is used independent of the number of target proteins and RNAs. (B) Confocal image of 4-plex IHC + RNA-ISH in mammalian cells on a slide; $0.13 \times 0.13 \mu \mathrm{m}$ pixels; maximum intensity z-projection. Targets: PCNA (protein; Alexa488), HSP60 (protein; Alexa546), U6 (RNA,; Alexa594), ACTB (mRNA; Alexa647). Sample: HeLa cells. (C) Confocal image of 4-plex IHC + RNA-ISH in FFPE mouse brain sections; $0.16 \times 0.16 \mu$ m pixels. Targets: TH (protein; Alexa488), MBP (protein; Alexa546), Prkcd (mRNA; Alexa647), Slc17a7 (mRNA; Alexa750). Sample: FFPE C57BL/6 mouse brain section (coronal); thickness: $5 \mu \mathrm{m}$. (D) Zoom of depicted regions of panel C. See Section S5.7 for additional data.

compete with varying degrees of autofluorescence. For protein imaging using $\mathrm{HCR} 1^{\circ} \mathrm{IHC}$ or $\mathrm{HCR} 2^{\circ} \mathrm{IHC}$, we favor protocols with two overnights (Figures $2 \mathrm{~B}$ and $3 \mathrm{~B}$ ), and for simultaneous protein and RNA imaging using HCR $1^{\circ} \mathrm{IHC}+\mathrm{RNA}-\mathrm{ISH}$ or $\mathrm{HCR} 2^{\circ} \mathrm{IHC}+\mathrm{RNA}-\mathrm{ISH}$, we favor protocols with three overnights (Figures 5A and 6A), allowing researchers to maintain a normal sleep schedule.

HCR RNA-ISH provides automatic background suppression throughout the protocol, ensuring that reagents will not generate amplified background even if they bind non-specifically within the sample (Choi et al., 2018). During the detection stage, each RNA target is detected by a probe set comprising one or more pairs of split-initiator probes, each carrying a fraction of HCR initiator i1 (Figure 1B). For a given probe pair, probes that hybridize specifically to their adjacent binding sites on the target RNA colocalize full initiator i1, enabling cooperative initiation of HCR signal amplification. Meanwhile, any individual probes that bind non-specifically in the sample do not colocalize full initiator i1, do not trigger HCR, and thus suppress generation of amplified background. During the amplification stage, automatic background suppression is inherent to HCR hairpins because polymerization is conditional on the presence of the initiator i1; individual h1 or h2 hairpins that bind non-specifically in the sample do not trigger formation of an amplification polymer. For HCR IHC, during the detection stage, each target protein is detected using primary or secondary antibody probes carrying one or more full i1 initiators (Figures 1CD). Hence, if a probe binds nonspecifically in the sample, initiator i1 will nonetheless trigger HCR, generating amplified background. As a result, it is important to use antibody probes that are highly selective for their targets, and to wash unused antibody probes from the sample. Nonetheless, during the amplification stage, kinetically trapped HCR hairpins provide automatic background suppression for protein targets just as they do for RNA targets, ensuring that any hairpins that bind non-specifically in the sample do not trigger growth of an HCR amplification polymer. For experiments using HCR IHC + RNA-ISH to image protein and RNA targets simultaneously, RNA targets enjoy automatic background suppression throughout the protocol, while protein targets rely on selective antibody binding to suppress background during the detection stage, combined with automatic background suppression during the amplification stage. 
A Protein detection stage

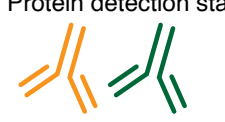

Add all unlabeled $1^{\circ}$ antibody probes
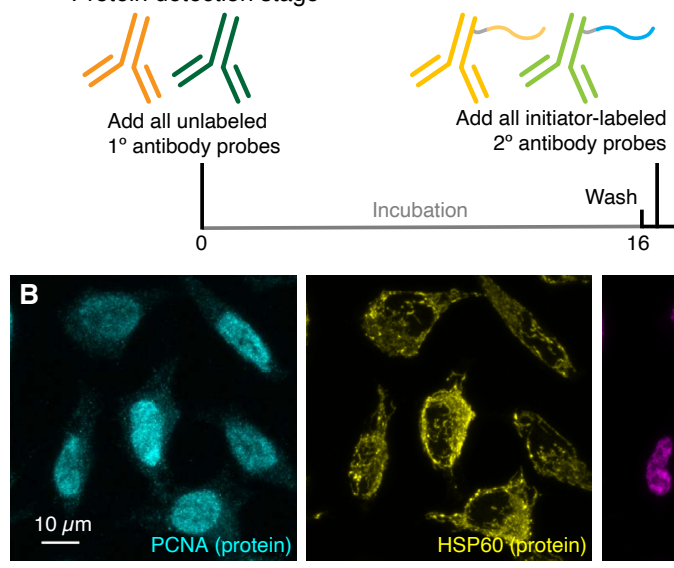

Add all initiator-labeled

$2^{\circ}$ antibody probes Add all split-initiator probe sets
RNA detection stage

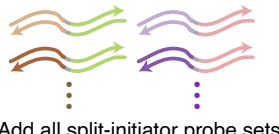

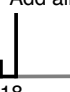

Incubation

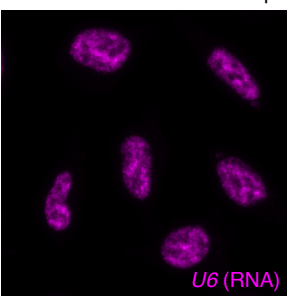

Amplification stage (all targets)

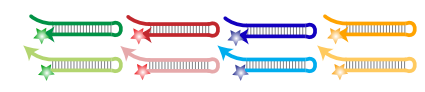

Add all HCR amplifiers

Experimental time (h)
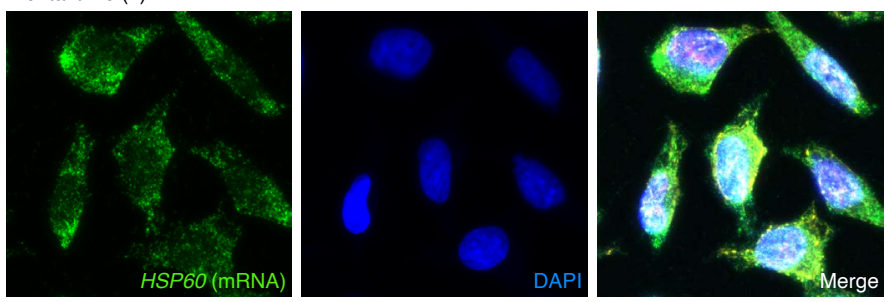

C
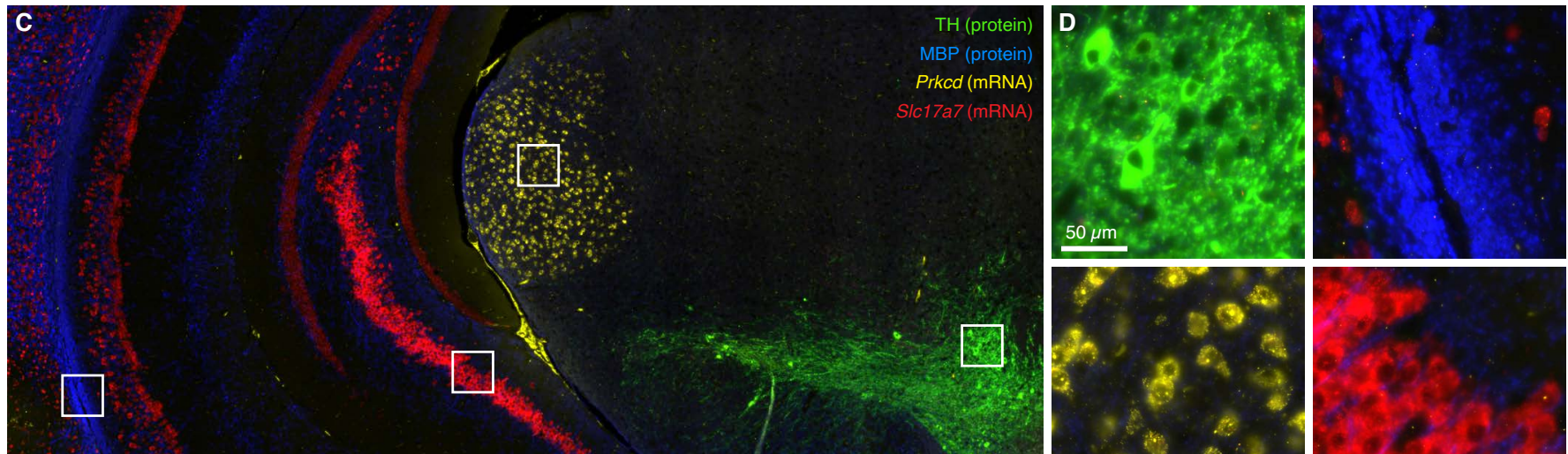

$500 \mu \mathrm{m}$
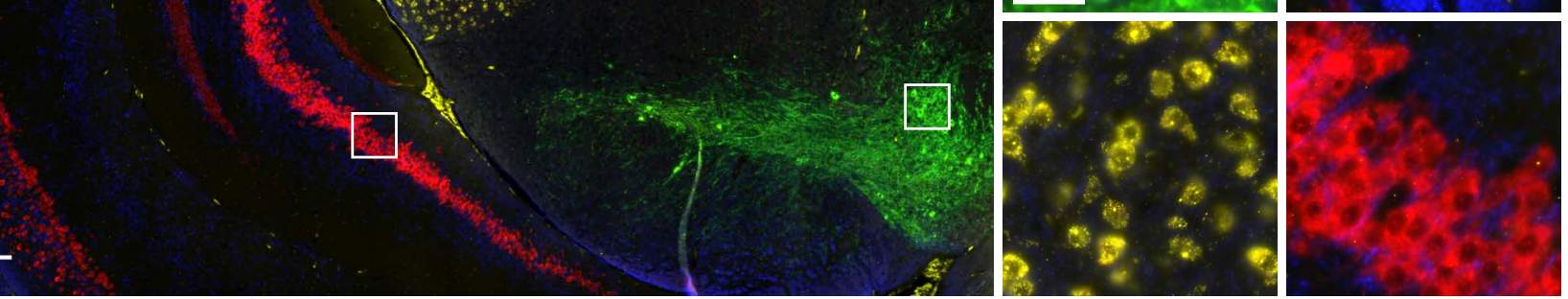

Fig. 6: Simultaneous multiplexed protein and RNA imaging via HCR $2^{\circ}$ IHC + HCR RNA-ISH using unlabeled primary antibody probes and initiator-labeled secondary antibody probes for protein targets, split-initiator DNA probes for RNA targets, and simultaneous HCR signal amplification for all targets. (A) 3-stage IHC + RNA-ISH protocol. Protein detection stage: unlabeled primary antibody probes bind to protein targets; wash; initiator-labeled secondary antibody probes bind to primary antibody probes; wash. RNA detection stage: split-initiator DNA probes bind to RNA targets; wash. Amplification stage: initiators trigger self-assembly of fluorophore-labeled HCR hairpins into tethered fluorescent amplification polymers; wash. For multiplexed experiments, the same 3-stage protocol is used independent of the number of target proteins and RNAs. (B) Confocal image of 4-plex IHC + RNA-ISH in mammalian cells on a slide; $0.13 \times 0.13 \mu \mathrm{m}$ pixels; maximum intensity z-projection. Targets: PCNA (protein; Alexa488), HSP60 (protein; Alexa546), U6 (RNA,; Alexa594), HSP60 (mRNA; Alexa647). Sample: HeLa cells. (C) Confocal image of 4-plex IHC + RNA-ISH in FFPE mouse brain sections; $0.16 \times 0.16 \mu \mathrm{m}$ pixels. Targets: TH (protein; Alexa488), MBP (protein; Alexa546), Prkcd (mRNA; Alexa647), Slc17a7 (mRNA; Alexa750). Sample: FFPE C57BL/6 mouse brain section (coronal); thickness: $5 \mu \mathrm{m}$. (D) Zoom of depicted regions of panel C. See Section S5.8 for additional data.

For RNA targets, we have previously shown that multiplexed qHCR imaging enables bi-directional quantitative discovery (Trivedi et al., 2018): read-out from anatomical space to expression space to discover co-expression relationships in selected regions of the sample; read-in from expression space to anatomical space to discover those anatomical locations in which selected gene co-expression relationships occur. Here, by validating high-accuracy, high-precision, high-resolution qHCR imaging for protein targets, read-out/read-in analyses can now be performed for RNA and protein targets simultaneously, offering biologists, drug developers, and pathologists a significantly expanded window for analyzing biological circuits in an anatomical context.

\section{MATERIALS AND METHODS}

Probes, amplifiers, and buffers. Details on the probes, amplifiers, and buffers for each experiment are displayed in Table S2 for HCR $1^{\circ} \mathrm{IHC}$, Table S3 for HCR $2^{\circ} \mathrm{IHC}$, and Table S4 for HCR RNA-ISH.
HCR IHC with/without HCR RNA-ISH. HCR $1^{\circ} \mathrm{IHC}$ with or without HCR RNA-ISH was performed using the protocols detailed in Sections S3. HCR $2^{\circ} \mathrm{IHC}$ with or without HCR RNA-ISH was performed using the protocols detailed in Sections S4. Strictly speaking, the cultured cell studies represent immunocytochemistry (ICC) rather than IHC; for notational simplicity, we use the term IHC uniformly in the main text but denote protocols for cultured cells as ICC in the supplementary information. For 5-channel imaging of HeLa cells (Figures 5B, S33-S34, 6B, S37-S38) the above protocols were modified as follows to enable imaging on an upright confocal microscope: cells were grown on a chambered slide with removable chambers (Ibidi, Cat. \#81201); prior to imaging, the silicone chambers were removed and cells were mounted with ProLong glass antifade mountant with NucBlue (Thermo Fisher Scientific Cat. \#P36981) according to the manufacturer's instructions.

Experiments were performed in HeLa cells (ATCC Cat. \# CRM-CCL-2), human embryonic kidney (HEK) 293T cells (ATCC Cat. \# CRL-3216), FFPE C57BL/6 mouse brain sections (coronal; thickness $5 \mu \mathrm{m}$, Acepix Biosciences Cat. \# 
bioRxiv preprint doi: https://doi.org/10.1101/2021.06.02.446311; this version posted June 2, 2021. The copyright holder for this preprint (which was not certified by peer review) is the author/funder. All rights reserved. No reuse allowed without permission.

7011-0120), FFPE human breast tissue sections (thickness 5 $\mu \mathrm{m}$; Acepix Biosciences Cat. \# 7310-0620), and whole-mount zebrafish embryos (fixed $27 \mathrm{hpf}$ ). Procedures for the care and use of zebrafish embryos were approved by the Caltech IACUC.

Confocal microscopy. Confocal microscopy was performed using a Zeiss LSM 800 inverted confocal microscope or a Zeiss LSM 880 with Fast Airyscan upright confocal microscope. All confocal images are displayed without background subtraction. See Table S5 for details on the microscope, objective, excitation lasers, beam splitters, emission bandpass filters used for each experiment.

Epifluorescence microscopy. Epifluorescence microscopy was performed using a Leica THUNDER Imager 3D cell culture epifluorescence microscope equipped with a Leica LED8 multiLED light source and sCMOS camera (Leica DFC9000 GTC). All epifluorescence images are displayed with instrument noise subtracted but without background subtraction. See Table S6 for details on the objective, excitation wavelengths, and filters used for each experiment.

Image analysis. Image analysis was performed as detailed in Section S2.6 of the supplementary material including: definition of raw pixel intensities, measurement of signal, background, and signal-to-background, measurement of background components, calculation of normalized subcellular voxel intensities for qHCR imaging.

\section{Acknowledgments}

We thank F. Chen for discussions, M.E. Bronner for reading a draft of the manuscript, and the following resources within the Beckman Institute at Caltech: A. Collazo of the Biological Imaging Facility for assistance with imaging, G. Shin of Molecular Technologies for providing HCR reagents, and the Zebrafish Facility for providing zebrafish embryos.

\section{Competing interests}

The authors declare competing financial interests in the form of patents, pending patent applications, and the startup company Molecular Instruments, Inc.

\section{Author contributions}

Conceptualization: N.A.P.; Methodology: M.S., M.C.L., S.J.S., N.H., H.M.T.C., N.A.P.; Validation: M.S., S.J.S., R.I.; Investigation: M.S., M.C.L, S.J.S., R.I., N.H.; Writing - original draft: N.A.P.; Writing - review \& editing: all; Visualization: M.S., R.I., S.J.S.; Supervision: M.C.L., H.M.T.C., and N.A.P.; Project administration: H.M.T.C. and N.A.P.; Funding acquisition: H.M.T.C. and N.A.P.

\section{Funding}

This work was funded by the National Institutes of Health (NIBIB R01EB006192, NIGMS R44GM140796), by DARPA (HR0011-17-2-0008; the findings are those of the authors and should not be interpreted as representing the official views or policies of the U.S. Government), and by the Beckman Institute at Caltech (Programmable Molecular Technology Center, PMTC)

\section{Supplementary information}

Supplementary information available online.

\section{References}

Acloque, H., Wilkinson, D. G., \& Nieto, M. A. (2008). In situ hybridization analysis of chick embryos in whole-mount and tissue sections. Pages 169-185 of: Bronner-Fraser, M. (ed), Avian Embryology, 2nd Edition. Methods in Cell Biology, vol. 87. San Diego, CA: Elsevier Academic Press.

Ahnfelt-Ronne, J., Jorgensen, M. C., Hald, J., Madsen, O. D., Serup, P., \& Hecksher-Sorensen, J. (2007). An improved method for three-dimensional reconstruction of protein expression patterns in intact mouse and chicken embryos and organs. J Histochem Cytochem, 55(9), 925-30.

Barroso-Chinea, P., Aymerich, M. S., Castle, M. M., Perez-Manso, M., Tunon, T., Erro, E., \& Lanciego, J. L. (2007). Detection of two different mRNAs in a single section by dual in situ hybridization: A comparison between colorimetric and fluorescent detection. J. Neurosci. Methods, 162(1-2), 119-128.

Bushnell, S., Budde, J., Catino, T., Cole, J., Derti, A., Kelso, R., Collins, M. L., Molino, G., Sheridan, P., Monahan, J., \& Urdea, M. (1999). ProbeDesigner: For the design of probesets for branched DNA (bDNA) signal amplification assays. Bioinformatics, 15(5), 348-355.

Capodieci, P., Donovan, M., Buchinsky, H., Jeffers, Y., Cordon-Cardo, C., Gerald, W., Edelson, J., Shenoy, S. M., \& Singer, R. H. (2005). Gene expression profiling in single cells within tissue. Nat. Methods, 2(9), 663-665.

Chan, P. M., Yuen, T., Ruf, F., Gonzalez-Maeso, J., \& Sealfon, S. C. (2005). Method for multiplex cellular detection of mRNAs using quantum dot fluorescent in situ hybridization. Nucleic Acids Res., 33(18), e161.

Choi, H. M. T., Chang, J. Y., Trinh, L. A., Padilla, J. E., Fraser, S. E., \& Pierce, N. A. (2010). Programmable in situ amplification for multiplexed imaging of mRNA expression. Nat. Biotechnol., 28(11), 1208-12.

Choi, H. M. T., Beck, V. A., \& Pierce, N. A. (2014). Next-generation in situ hybridization chain reaction: Higher gain, lower cost, greater durability. ACS Nano, 8(5), 4284-4294.

Choi, H. M. T., Calvert, C. R., Husain, N., Huss, D., Barsi, J. C., Deverman, B. E., Hunter, R. C., Kato, M., Lee, S. M., Abelin, A. C. T., Rosenthal, A. Z., Akbari, O. S., Li, Y., Hay, B. A., Sternberg, P. W., Patterson, P. H., Davidson, E. H., Mazmanian, S. K., Prober, D. A., van de Rijn, M., Leadbetter, J. R., Newman, D. K., Readhead, C., Bronner, M. E., Wold, B., Lansford, R., Sauka-Spengler, T., Fraser, S. E., \& Pierce, N. A. (2016). Mapping a multiplexed zoo of mRNA expression. Development, 143, 3632-3637.

Choi, H. M. T., Schwarzkopf, M., Fornace, M. E., Acharya, A., Artavanis, G., Stegmaier, J., Cunha, A., \& Pierce, N. A. (2018). Third-generation in situ hybridization chain reaction: Multiplexed, quantitative, sensitive, versatile, robust. Development, 145, dev165753.

Clay, H., \& Ramakrishnan, L. (2005). Multiplex fluorescent in situ hybridization in zebrafish embryos using tyramide signal amplification. Zebrafish, 2(2), 105-111.

Collins, M. L., Irvine, B., Tyner, D., Fine, E., Zayati, C., Chang, C. A., Horn, T., Ahle, D., Detmer, J., Shen, L.-P., Kolberg, J., Bushnell, S., Urdea, M. S., \& Ho, D. D. (1997). A branched DNA signal amplification assay for quantification of nucleic acid targets below 100 molecules $/ \mathrm{ml}$. Nucleic Acids Res., 25(15), 2979-2984.

Coons, A. H., Creech, H. J., \& Jones, R. N. (1941). Immunological properties of an antibody containing a fluorescent group. Proc. Soc. Exp. Biol. Med., 47(2), 200-202.

Cox, K. H., Deleon, D. V., Angerer, L. M., \& Angerer, R. C. (1984). Detection of mRNAs in sea urchin embryos by in situ hybridization using asymmetric RNA probes. Dev. Biol., 101(2), 485-502.

Denkers, N., Garcia-Villalba, P., Rodesch, C. K., Nielson, K. R., \& Mauch, T. J. (2004). FISHing for chick genes: Triple-label whole-mount fluorescence in situ hybridization detects simultaneous and overlapping gene expression in avian embryos. Dev. Dyn., 229(3), 651-657.

Dirks, R. M., \& Pierce, N. A. (2004). Triggered Amplification by Hybridization Chain Reaction. Proc. Natl. Acad. Sci. U. S. A., 101(43), 15275-15278.

Femino, A., Fay, F. S., Fogarty, K., \& Singer, R. H. (1998). Visualization of single RNA transcripts in situ. Science, 280(5363), 585-590.

Fujisawa, S., Yarilin, D., Fan, N., Turkekul, M., Xu, K., Barlas, A., \& ManovaTodorova, K. (2015). Understanding the three-dimensional world from twodimensional immunofluorescent adjacent sections. J Pathol Inf., 6, 27.

Gall, J. G., \& Pardue, M. L. (1969). Formation and detection of RNA-DNA hybrid molecules in cytological preparations. Proc. Natl. Acad. Sci. U. S. A., 63 378-383.

Glass, G., Papin, J. A., \& Mandell, J. W. (2009). SIMPLE: A Sequential Immunoperoxidase Labeling and Erasing Method. J Histochem Cytochem, 57(10), 899-905.

Harland, R. M. (1991). In situ hybridization: An improved whole-mount method for Xenopus embryos. Methods Cell Biol., 36, 685-695.

Hughes, S. C., \& Krause, H. M. (1998). Double labeling with fluorescence in situ hybridization in Drosophila whole-mount embryos. BioTechniques, 24(4), 530-532.

Husain, N. 2016. Mapping mRNA and protein expression with high signal-tobackground in diverse organisms. PhD Thesis, California Institute of Technology.

Kerstens, H. M. J., Poddighe, P. J., \& Hanselaar, A. G. J. M. (1995). A novel in-situ hybridization signal amplification method based on the deposition of biotinylated tyramine. J. Histochem. Cytochem., 43(4), 347-352.

Kishi, J. Y., Lapan, S. W., Beliveau, B. J., West, E. R., Zhu, A., Sasaki, H. M., Saka, S. K., Wang, Y., Cepko, C. L., \& Yin, P. (2019). SABER amplifies FISH: Enhanced multiplexed imaging of RNA and DNA in cells and tissues. Nat. Methods, 16(6), 533-544.

Kislauskis, E. H., Li, Z., Singer, R. H., \& Taneja, K. L. (1993). Isoform-specific 3'-untranslated sequences sort $\alpha$-cardiac and $\beta$-cytoplasmic actin messenger RNAs to different cytoplasmic compartments. J. Cell Biol., 123(1), 165-172.

Koos, B., Cane, G., Grannas, K., Löf, L., Arngården, L., Heldin, J., Clausson, C. M., Klaesson, A., Hirvonen, M. K., de Oliveira, F. M. S., Talibov, V. O., Pham, N. T., Auer, M., Danielson, U. H., Haybaeck, J., KamaliMoghaddam, M., \& Söderberg, O. (2015). Proximity-dependent initiation of hybridization chain reaction. Nat. Commun., 6, 7294.

Kosman, D., Mizutani, C. M., Lemons, D., Cox, W. G., McGinnis, W., \& Bier, E. (2004). Multiplex detection of RNA expression in Drosophila embryos. Science, 305, 846 . 
Larsson, C., Koch, J., Nygren, A., Janssen, G., Raap, A. K., Landegren, U., \& Nilsson, M. (2004). In situ genotyping individual DNA molecules by target-primed rolling-circle amplification of padlock probes. Nat. Methods, 1(3), 227-232.

Larsson, C., Grundberg, I., Soderberg, O., \& Nilsson, M. (2010). In situ detection and genotyping of individual mRNA molecules. Nat. Methods, 7(5), 395-397.

Lehmann, R., \& Tautz, D. (1994). In situ hybridization to RNA. Pages 575-598 of: Goldstein, L. S. B., \& Fyrberg, E. A. (eds), Drosophila melanogaster: Practical uses in cell and molecular biology. Methods in Cell Biology, vol. 44. San Diego, CA: Elsevier Academic Press.

Levsky, J. M., Shenoy, S. M., Pezo, R. C., \& Singer, R. H. (2002). Single-cell gene expression profiling. Science, 297, 836-840.

Lin, R., Feng, Q., Li, P., Zhou, P., Wang, R., Liu, Z., Wang, Z., Qi, X., Tang, N., Shao, F., \& Luo, M. (2018). A hybridization-chain-reaction-based method for amplifying immunosignals. Nat. Methods, 15(4), 275-278.

Macechko, P. T., Krueger, L., Hirsch, B., \& Erlandsen, S. L. (1997). Comparison of immunological amplification versus enzymatic deposition of fluorochromeconjugated tyramide as detection systems for FISH. J. Histochem. Cytochem., 45(3), 359-363.

Mitchell, R. T., Camacho-Moll, M. E., Macdonald, J., Anderson, R. A., Kelnar, C. J. H., O'Donnell, M., Sharpe, R. M., Smith, L. B., Grigor, K. M., Wallace, W. H. B., Stoop, H., Wolffenbuttel, K. P., Donat, R., Saunders, P. T. K., \& Looijenga, L. H. J. (2014). Intratubular germ cell neoplasia of the human testis: Heterogeneous protein expression and relation to invasive potential. Mod Pathol, 27(9), 1255-1266.

Nieto, M. A., Patel, K., \& Wilkinson, D. G. (1996). In situ hybridization analysis of chick embryos in whole mount and tissue sections. Pages 219-235 of: BronnerFraser, M. (ed), Methods in Avian Embryology. Methods in Cell Biology, vol. 51. San Diego, CA: Elsevier Academic Press.

Pernthaler, A., Pernthaler, J., \& Amann, R. (2002). Fluorescence in situ hybridization and catalyzed reporter deposition for the identification of marine bacteria. Appl. Environ. Microbiol., 68(6), 3094-3101.

Piette, D., Hendrickx, M., Willems, E., Kemp, C. R., \& Leyns, L. (2008). An optimized procedure for whole-mount in situ hybridization on mouse embryos and embryoid bodies. Nat. Protoc., 3(7), 1194-1201.

Player, A. N., Shen, L.-P., Kenny, D., Antao, V. P., \& Kolberg, J. A. (2001). Single-copy gene detection using branched DNA (bDNA) in situ hybridization. J. Histochem. Cytochem., 49(5), 603-611.

Psychoyos, D., \& Finnell, R. (2009). Method for whole mount antibody staining in chick. J Vis Exp, e956.

Qian, X., \& Lloyd, R. V. (2003). Recent developments in signal amplification methods for in situ hybridization. Diagn. Mol. Pathol., 12(1), 1-13.

Qian, X., Jin, L., \& Lloyd, R. V. (2004). In situ hybridization: Basic approaches and recent development. J. Histotechnol., 27(1), 53-67.

Raj, A., van den Bogaard, P., Rifkin, S. A., van Oudenaarden, A., \& Tyagi, S. (2008). Imaging individual mRNA molecules using multiple singly labeled probes. Nat. Methods, 5(10), 877-879.

Ramos-Vara, J. A., \& Miller, M. A. (2014). When tissue antigens and antibodies get along: Revisiting the technical aspects of immunohistochemistry-the red, brown, and blue technique. Vet Pathol, 51(1), 42-87.

Rosen, B., \& Beddington, R. S. P. (1993). Whole-mount in situ hybridization in the mouse embryo: Gene-expression in three dimensions. Trends Genet., 9(5), $162-166$.

Saka, S. K., Wang, Y., Kishi, J. Y., Zhu, A., Zeng, Y., Xie, W., Kirli, K., Yapp, C., Cicconet, M., Beliveau, B. J., Lapan, S. W., Yin, S., Lin, M., Boyden, E. S., Kaeser, P. S., Pihan, G., Church, G. M., \& Yin, P. (2019). Immuno-SABER enables highly multiplexed and amplified protein imaging in tissues. Nat. Biotechnol., 37(9), 1080-1090.

Schweitzer, B., \& Kingsmore, S. (2001). Combining nucleic acid amplification and detection. Curr. Opin. Biotechnol., 12, 21-27.

Shah, S., Lubeck, E., Schwarzkopf, M., He, T.-F., Greenbaum, A., Sohn, C. H., Lignell, A., Choi, H. M. T., Gradinaru, V., Pierce, N. A., \& Cai, L. (2016). Single-molecule RNA detection at depth via hybridization chain reaction and tissue hydrogel embedding and clearing. Development, 143, 2862-2867.

Sillitoe, R. V., \& Hawkes, R. (2002). Whole-mount immunohistochemistry: A highthroughput screen for patterning defects in the mouse cerebellum. J Histochem Cytochem, 50(2), 235-44.

Silverman, A., \& Kool, E. (2007). Oligonucleotide probes for RNA-targeted fluorescence in situ hybridization. Adv. Clin. Chem., 43, 79-115.

Stack, E. C., Wang, C. C., Roman, K. A., \& Hoyt, C. C. (2014). Multiplexed immunohistochemistry, imaging, and quantitation: A review, with an assessment of Tyramide signal amplification, multispectral imaging and multiplex analysis. Methods, 70(1), 46-58.

Staudt, N., Muller-Sienerth, N., Fane-Dremucheva, A., Yusaf, S. P., Millrine, D., \& Wright, G. J. (2015). A panel of recombinant monoclonal antibodies against zebrafish neural receptors and secreted proteins suitable for wholemount immunostaining. Biochem Biophys Res Commun, 456(1), 527-33.

Takakura, N., Yoshida, H., Ogura, Y., Kataoka, H., Nishikawa, S., \& Nishikawa, S. (1997). PDGFR alpha expression during mouse embryogenesis: Immunolocalization analyzed by whole-mount immunohistostaining using the monoclonal anti-mouse PDGFR alpha antibody APA5. J Histochem $\mathrm{Cy}$ tochem, 45(6), 883-93.

Tautz, D., \& Pfeifle, C. (1989). A non-radioactive in situ hybridization method for the localization of specific RNAs in Drosophila embryos reveals translational control of the segmentation gene hunchback. Chromosoma, 98, 81-85.

Thisse, B., Heyer, V., Lux, A., Alunni, V., Degrave, A., Seiliez, I., Kirchner, J.,
Parkhill, J. P., \& Thisse, C. (2004). Spatial and temporal expression of the zebrafish genome by large-scale in situ hybridization screening. Pages 505-519 of: Detrich III, H. W. D., Zon, L. I., \& Westerfield, M. (eds), The Zebrafish: 2nd Edition Genetics Genomics and Informatics. Methods in Cell Biology, vol. 77. San Diego, CA: Elsevier Academic Press.

Thisse, C., \& Thisse, B. (2008). High-resolution in situ hybridization to wholemount zebrafish embryos. Nat. Protoc., 3(1), 59-69.

Tóth, Z. E., \& Mezey, E. (2007). Simultaneous Visualization of Multiple Antigens with Tyramide Signal Amplification using Antibodies from the same Species. J Histochem Cytochem., 55(6), 545-554.

Trivedi, V., Choi, H. M. T., Fraser, S. E., \& Pierce, N. A. (2018). Multidimensional quantitative analysis of mRNA expression within intact vertebrate embryos. Development, 145, dev156869.

Tsujikawa, T., Kumar, S., Borkar, R. N., Azimi, V., Thibault, G., Chang, Y. H., Balter, A., Kawashima, R., Choe, G., Sauer, D., El Rassi, E., Clayburgh, D. R., Kulesz-Martin, M. F., Lutz, E. R., Zheng, L., Jaffee, E. M., Leyshock, P., Margolin, A. A., Mori, M., Gray, J. W., Flint, P. W., \& Coussens, L. M. (2017). Quantitative multiplex immunohistochemistry reveals myeloid-inflamed tumor-immune complexity associated with poor prognosis. Cell Rep, 19(1), 203-217.

Wallner, G., Amann, R., \& Beisker, W. (1993). Optimizing fluorescent in situ hybridization with rRNA-targeted oligonucleotide probes for flow cytometric identification of microorganisms. Cytometry, 14(2), 136-143.

Wang, F., Flanagan, J., Su, N., Wang, L.-C., Bui, S., Nielson, A., Wu, X. Y., Vo, H.-T., Ma, X.-J., \& Luo, Y. L. (2012). RNAscope: A novel in situ RNA analysis platform for formalin-fixed, paraffin-embedded tissues. J. Mol. Diagn., 14(1), 22-29.

Weiszmann, R., Hammonds, A. S., \& Celniker, S. E. (2009). Determination of gene expression patterns using high-throughput RNA in situ hybridization to whole-mount Drosophila embryos. Nat. Protoc., 4(5), 605-618.

Wiedorn, K. H., Kuhl, H., Galle, J., Caselitz, J., \& Vollmer, E. (1999). Comparison of in-situ hybridization, direct and indirect in-situ PCR as well as tyramide signal amplification for the detection of HPV. Histochem. Cell Biol., 111, 8995.

Zhou, H., Bouwman, K., Schotanus, M., Verweij, C., Marrero, J. A., Dillon, D., Costa, J., Lizardi, P., \& Haab, B. B. (2004). Two-color, rolling-circle amplification on antibody microarrays for sensitive, multiplexed serum-protein measurements. Genome Biol., 5(4), R28.

Zhou, Y., Calciano, M., Hamann, S., Leamon, J. H., Strugnell, T., Christian, M. W., \& Lizardi, P. M. (2001). In situ detection of messenger RNA using digoxigenin-labeled oligonucleotides and rolling circle amplification. Exp. Mol. Pathol., 70, 281-288. 